\title{
Research on the teaching of advanced mathematics into the idea of mathematical modeling
}

\author{
Sun xiaoying ${ }^{1,}$, Xu chongkun $^{2}$ \\ ${ }^{1,2}$ Nanchang Institute of Science and Technology, 330108 \\ asunxiaoying@126.com
}

\begin{abstract}
Keywords: Thought integration; Mathematical modeling; Advanced mathematics; Teaching thought; Teaching reform.
\end{abstract}

\begin{abstract}
Advanced mathematics is a compulsory course for science and engineering students to enter university, which is also an important basic course. This course has a very important role in deepening the theoretical basis of learning, enhancing the training of basic skills, improving mathematical accomplishment, and developing the ability of mathematics. But our current higher mathematics teaching is mostly based on a "target teaching", calculation methods and techniques in the teaching process to explain the main concepts, the main theorem, the purpose is to let students pass the final exam, a serious departure from the actual production and life, most students don't know what is the use of mathematics, just to learn mathematics and mathematics, lack of awareness and ability to apply mathematical knowledge to solve practical problems in life. So it is very important to integrate mathematical modeling into the teaching of advanced mathematics, to cultivate students' sense of innovation, and to apply the knowledge to solve practical problems. In the higher mathematics teaching process, students will find no interest in mathematics learning, and some students even had the number of awe. Therefore, in order to meet the needs of today's scientific development and training target, the teaching content, from the number of teaching models and teaching methods in three aspects, the mathematical modeling of the ideological infiltration in the problem of higher mathematics teaching process is discussed.
\end{abstract}

\section{Introduction}

Mathematical modeling refers to some specific objects in the real world, for a particular purpose, make some important simplification and assumptions, a mathematical structure is obtained using appropriate mathematical tools, and use it to explain certain realistic state, predict the future state of the object, provide processing object optimization decision and control, design for meeting the needs of a certain product, etc., this is the basic idea of mathematical modeling. Through many years practice of the national college students' mathematical modeling competition shows that mathematical modeling in cultivating students' observation, imagination, logical thinking ability and analysis, the solution actual problem ability has played a big role, but limited to the size of the competition and the demand for entry level[1], participate in mathematical modeling contest is only a small number of students. Although many colleges and universities each year students mathematical modeling elective course and the mathematical modeling of training, but the course to the student mathematics knowledge the demand is higher, so these courses are not suitable for popularization of education. Will comprehensively improve the quality of college students and cultivating innovative applied talents, the responsibility should fall on the usual traditional mathematics course, is the carrier of advanced mathematics is a very ideal. In everyday in the process of higher mathematics teaching, will find that some students for higher mathematics study for the test, the interest in learning higher mathematics dull; There are some students is to learn high number awe; Special and individual student of university courses in higher mathematics question: with not too many professional association, why spend so much energy to learn high number. This is because the student has not been able to fundamentally understand the foundation of higher mathematics for its major, key. So in order 
to adapt to the needs of the development of today's science and college training objectives: training high-quality, high-level applied talents. Teachers should be in of day-to-day practical problems in the teaching process, and use of mathematical modeling thought, combined with high content, we learned from set out actually, gradually inspire students' interest in learning of higher mathematics, to explore, research to make its own. First of all should be clear: the students of higher mathematics in university professional learning process, it will act as the role of a tool, is the foundation of learning other courses, the key. By the number of higher learning, exercise the abstract thinking ability of students to apply mathematical knowledge as the goal. It is for this reason, the teacher in the teaching process should be combined with the practical problems will be high for several contents vivid and interesting with attractive. And mathematical modeling thought has the universality and practicability of not only can be used in more traditional related disciplines such as mechanics, astronomy, etc., at the same time can be compared in the present popular biological, cultural and economic development puts glorious greatly, medicine and other subjects. So combining with the content of higher mathematics, the appropriate to introduce mathematical modeling knowledge and ideas to students, thus highlights the importance of mathematical thinking in college professional courses[2].

\section{Bottleneck in higher mathematics teaching}

The teaching method is lack of flexibility. Rigidity of single teaching means, teaching methods and some student interest is not high. It is understood that at present most of the higher mathematics teaching in higher vocational colleges is still in yun nan province with the blackboard writing teaching of the non-computer majors. Due to the higher mathematics teaching theory, application, attention to the cultivation of deductive reasoning ability, neglecting students mathematical theories and methods to solve the actual problem ability training, the students feel and profound theoretical knowledge of higher mathematics in the abstract, the fear of difficulties to the complex calculation, at the same time, many students feel hard to learn math, but no help to their own professional, work in the future, so the heart germination of "high number of useless theory", by the high number of learning has strong resistance, but in order to pass the exam and had to passively study, because interest is not high, poor learning nature. Mathematics and the coordination of the professional related discipline is not enough, can't support their professional development better. Since the $1970 \mathrm{~s}$, with the rapid development of computer and mathematics at an unprecedented rate penetration to other disciplines, the application of the breadth and depth are also constantly strengthen, for some science and engineering professionals, advanced mathematics has become a indispensable professional basis, however, at present the higher mathematics teaching in higher vocational colleges has turned a blind eye to this, still on pure mathematics teaching in isolation, behind closed doors, not from a professional global to arrange their students learn mathematics teaching, better service for this professional learning.

Students can not apply what they have learned. The number of hours in higher mathematics is basically the class the most students in all courses, but the learning effect is not very ideal, every year each semester there are many students failed, most students of higher mathematics. I don't know how to learn, only part of theory and calculation method can't apply. Analysis of the main reasons are as follows: (1) the number of hours relative to its content or less, teachers in order to allow students to pass the exam, to speak more emphasis on the examination place, a little about the historical background of the concept and practice of some application problems. (2) the key concepts, theory, calculation methods, lack of vivid and interesting, make the students feel that learning mathematics is boring, can not fully mobilize the enthusiasm and initiative of the students. (3) most of the traditional "blackboard" teaching, not the use of a lot of media to help students more intuitive understanding of knowledge points, the lack of novelty classroom. (4) few examples of students familiar with the life of life in the classroom illustrate the mathematical problems, can not be very good to stimulate the enthusiasm of students thinking, to attract the attention of students. (5) the opportunity to use mathematical knowledge to practice in the course of students. 
Lack of mathematical modeling ideas. A mathematical model of the process is called mathematical modeling, mathematical model refers to a specific object, to a feature of target, according to the unique inherent laws, make some simplifying assumptions are necessary, are mathematics, letters or other mathematical symbols, describe the mathematical formula, specific object number rule or algorithm graphics. It can explain the actual state of a particular phenomenon or the future state of the object, or provide the optimal decision or control of the object to be processed. The characteristics of the mathematical model: (1) the essential characteristics of mathematical form which can be used to reflect the nature and the social reality of a phenomenon; (2) it can be through a mathematical abstraction, obtained the corresponding formula, and can be generalized and applied to solve the similar problems; (3) using computer mathematics the algorithm of model programming or algorithmic language to use. If the mathematical model according to different applications, can be divided into: traffic model, ecological model, environment model, mathematical model, mathematical model of medical economics; if the method according to the established mathematical model can be divided into: elementary mathematics model, geometry model, differential equation model, graph model etc.. It is precisely because the mathematical model of the establishment of the social economy, ecological environment, daily life and so on are of practical value, and can improve the ability of university students to explore, innovate, practice, etc.. Therefore, mathematical modeling has been booming at home and abroad, China's annual National College Students' mathematical modeling contest, the competition has become one of the most gold in china. But it is not enough to raise the students' interest in mathematics knowledge and modeling ideas by the competition of each year. As a teacher, we should introduce the idea of mathematical modeling in the process of daily mathematics teaching[3].

\section{The thinking and practice of integrating mathematical modeling into the teaching of advanced mathematics}

Strengthen the use of modern software. Improve teaching methods, strengthen the computer teaching, the use of Excel, MATLAB and other software to improve the visibility and application of mathematics teaching. Because of the higher mathematics teaching most of the traditional writing on the blackboard, the cramming method of teaching, dull, not conducive to stimulate students' enthusiasm for learning, the teaching effect is not ideal, teaching means and methods so we should reform the traditional teaching, using the computer, it requires students through self mastery of a mathematical software (such as MATLAB, Mathematical), so, in the teaching of mathematics, we can through the vivid graphics display to students with intuitive feelings, the computing function of the computer is convenient to communicate mathematical knowledge and practical problems, set up the students to use mathematical knowledge to solve practical problems of consciousness, improve mathematics knowledge application ability.

Encourage students to participate in modeling competitions. Encourage students in Higher Vocational Colleges to take part in the National Mathematical Modeling Contest of College students. At present, many higher vocational colleges due to various conditions, non professional mathematics has not yet organized students to participate in the national mathematical modeling contest, but in fact, because of Higher Vocational Colleges of science and engineering and the actual production and life more closely than mathematics, higher requirements on the application of mathematical knowledge to solve practical problems, should participate in the National Mathematical Modeling contest. Through the mathematical modeling contest, enthusiasm can not only stimulate students' learning, improve the learning interest, but also make students realize the idea of modeling, training students' creative thinking, the students for the future application, use mathematical knowledge to solve practical problems provides an example. Improving the examination methods of higher mathematics and increasing the ability of practice. For higher mathematics teaching, examination is the baton, if we still use the exam, only test students' mathematical theory level, so, quite a few students will pass the exam in order to study the effect of practice teaching will be greatly reduced. So, the idea of mathematical modeling into higher mathematics teaching practice, at the same time, we must reform 
the examination mode of higher mathematics, mathematics literacy theory examination is necessary, but we also want to join the practice examination, can be combined with the actual professional, a modeling problem, the ability to use mathematical knowledge to solve the major practical problems, the value proportion, I think is still in the theoretical examination, 6:4 or 7:3 are feasible. Only theory and practice together to examine, this can make the practical teaching really implemented, to achieve the desired results.

Increase practical contact. From the number of lectures on efforts to prove that due to the deletion of some of the mathematical theory and practical more closely related to daily life, practice teaching content. Through the optimization of the teaching content, to cultivate students through the analysis, logical reasoning, the purpose of solving mathematical problems. For example, the differential equation of this chapter, students should not only know how to solve the differential equation, also should understand the application of differential equations, can get drunk driving as a subject for students using mathematical model thought to discuss: the alcohol concentration in blood diffusion speed, for example, the onset time of the drug in human body etc.. In this way, not only can arouse students' interest in learning, but also to consolidate the learning content, and eventually achieve the inherent law to abstract objective things with the language of mathematics and methods, the purpose of solving the problem. Because in our daily teaching, the teaching mode is unified, light personality, too much emphasis on teaching materials, teaching requirements and the progress of the unity of the lack of levels, diversification. Can not be well adapted to the requirements of different professional, different training specifications. The lack of knowledge of the application of mathematics, the mathematical tools cannot be well utilized to solve practical problems related to professional. From the teaching methods, the present stage of a single Professor, examination reform and development. Mathematics teachers can not rely on the chalk and the blackboard will instill a high content to teach the students, should call the multimedia teaching as much as possible, but also the professional courses students take with high content, are discussed in the classroom, to arouse students' interest in learning. In the examination, not only the content and method of the study, but also the extension of mathematics knowledge and the ability to solve the problem should be examined[4].

An overview of the specific operation method. On the first class to introduce students to history of calculus, let students know that mathematics is to solve the actual problems in the production and life of abstraction out, this has reflected in the process of an important idea of mathematical modeling in mathematics thought. In the class can also mention some interesting problems such as appropriate, many girls wear high heels looks more beautiful, and that these problems can be used we learned mathematics knowledge to answer, it can arouse students' curiosity, learning enthusiasm and stimulate students. Mathematical concepts are the practical problems from the real life of abstraction out, teachers can take advantage of its origin, background, examples and process in teaching, based on the actual background of the problem solving process of abstraction and generalization, analysis of the introduction, let the student realize the method by practical problems to mathematical concepts in ways gradually, the idea of mathematical modeling and cultivation of students' awareness of the. The mathematical formula is an important part of students to master, when teachers tend to attach importance to the application of methods and computational techniques are introduced, in order to stimulate the enthusiasm of students better, teachers can choose a practical problem related to the content of the model demonstration, help students to practice, to deepen the understanding and formula master. For example, in the first chapter of the second important limits of the first chapter, it is required to have a good grasp of the important formula, teachers in the explanation, you can give an example of the population growth rate. Mathematics application problem is the basic way to investigate the ability of students to solve practical problems by using mathematical knowledge. It is a simple mathematical modeling problem, which involves the basic process of mathematical modeling thought and method. Therefore, after studying the theoretical knowledge of a chapter, one or two practical problems, to guide students to analyze, through abstraction, simplification and assumption, mathematical model is established and solved, solving practical problems, it can also cultivate and improve the students' analysis ability to solve practical problems. As the knowledge value after completion of the selection, some practical problems and professional students interested 
in or related, through modeling and solving the model to let the students to realize the application of mathematical knowledge in real life. Because of the special nature of mathematics, it is not ideal to use the multimedia to replace the blackboard completely, so the method is not desirable. But we can use the multimedia in the appropriate section, to help students to understand the mathematical knowledge and mathematical model, both to increase the novelty of the mathematics class can stimulate students' interest in learning. Quite a few chapters, can give students a simple mathematical modeling problem, cultivate their ability to use mathematical knowledge to solve practical problems and innovation ability. The total scores of our math grades including final grade and stage, can be arranged in a mathematical modeling problem at the end of a semester, students can finish, finally in the form of papers submitted, as part of a total score. In the final examination papers can be a combination of practical problems with the actual. Previously opened a mathematical test class, due to the small class of new teachers to teach, the effect is not ideal. In order to cultivate students' ability to practice mathematics, the experiment course is not little, which can be used as a part of advanced mathematics teaching in the course of advanced mathematics teaching. There are the National Mathematical Modeling Contest every year, but the number of participants is too small, most of the students do not have this opportunity, if within the school organization, students have the opportunity to participate, can exercise the students' practical ability, innovation ability and team spirit, and choose the good group to participate in the national competition, winning rate may be higher [5].

\section{Summary}

In the teaching of mathematical modeling ideas, training students to use the knowledge to solve practical problems, is the direction of the reform of mathematics education, mathematics is to use mathematics. So teachers should try to create opportunities for students to solve some practical problems in real life, to what. Therefore, we can not only pay attention to the teaching of theoretical knowledge of students, but also pay attention to the ability to train students to use mathematics, so that they really put mathematics as a tool to use. Otherwise is not to cultivate students' mathematical modeling thought, also from the daily life, this continuous cycle eventually makes students lose interest in learning, learning in a passive position, training objectives and needs to draw further apart of today's scientific development in Colleges and universities. And the thought of mathematical modeling can just make the students from the practical problems to extract mathematical problems. Not only can be a good combination of the mathematical knowledge, but also can effectively train students to take the initiative to think about the problem, the ability to solve problems. Therefore, in the teaching of mathematical modeling course will be appropriate, is an effective way for the purpose of scientific training and development of colleges and universities, this will is one of the important direction of teaching reform of higher mathematics.

\section{Acknowledgements}

Sponsored by jiangxi province department of education, Science and technology research project GJJ151244.

\section{References}

[1] Li Yao. Cultivation of vocational courses on Modeling of secondary vocational school students and creative application of [J]. Public technology. 2013 (02).

[2] Dong Xiao. The practice and research of "project lead, task driven" teaching method -- Taking "computer application foundation" course as an example [J]. Heihe education. 2012 (08).

[3] Liao Xiaolian, Chen Guohua. A mathematical modeling contest for the carrier to cultivate practical talents in practical innovation capacity [J]. Value engineering. 2010 (11). 
[4] Li Guoqiang, the gold. The existing problems and Countermeasures of the development of Vocational Education in China to investigate the effect of [J]. On adult education. 2009 (06).

[5] Liu Dongmei. Theoretical analysis of mathematical modeling teaching and research learning [J]. Journal of Shandong Normal University (NATURAL SCIENCE EDITION). 2008 (02). 